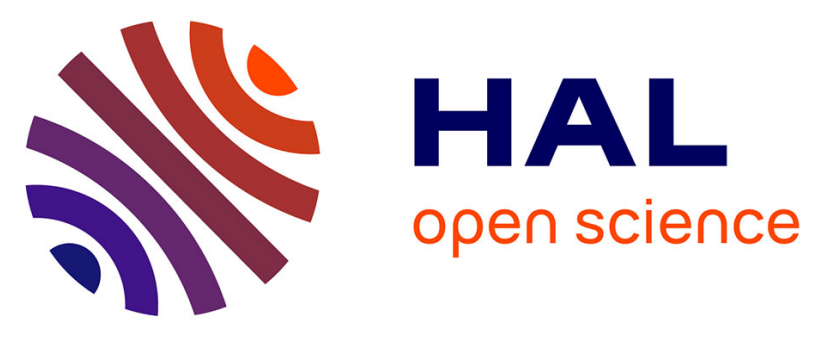

\title{
Block based image compression technique using rank reduction and wavelet difference reduction
}

\author{
Anastasia Bolotnikova, Pejman Rasti, Andres Traumann, Iiris Lüsi, Morteza \\ Daneshmand, Fatemeh Noroozi, Kadri Samuel, Suman Sarkar, Gholamreza \\ Anbarjafari
}

\section{To cite this version:}

Anastasia Bolotnikova, Pejman Rasti, Andres Traumann, Iiris Lüsi, Morteza Daneshmand, et al.. Block based image compression technique using rank reduction and wavelet difference reduction. Seventh International Conference on Graphic and Image ProcessingSeventh International Conference on Graphic and Image Processing (ICGIP 2015), 2015, Singapour, Singapore. 10.1117/12.2227994 . hal-02527962

\section{HAL Id: hal-02527962 \\ https://univ-angers.hal.science/hal-02527962}

Submitted on 24 Aug 2021

HAL is a multi-disciplinary open access archive for the deposit and dissemination of scientific research documents, whether they are published or not. The documents may come from teaching and research institutions in France or abroad, or from public or private research centers.
L'archive ouverte pluridisciplinaire HAL, est destinée au dépôt et à la diffusion de documents scientifiques de niveau recherche, publiés ou non, émanant des établissements d'enseignement et de recherche français ou étrangers, des laboratoires publics ou privés. 


\title{
Block Based Image Compression Technique Using Rank Reduction and Wavelet Difference Reduction
}

\author{
Anastasia Bolotnikova, Pejman Rasti, Andres Traumann, Iiris Lusi, Morteza Daneshmand, Fatemeh \\ Noroozi, Kadri Samuel, Suman Sarkar, and Gholamreza Anbarjafari, \\ iCV Research Group, Institute of Technology, University of Tartu, Nooruse 1, Tartu 50411, Estonia
}

\begin{abstract}
In this paper a new block based lossy image compression technique which is using rank reduction of the image and wavelet difference reduction (WDR) technique, is proposed. Rank reduction is obtained by applying singular value decomposition (SVD). The input image is divided into blocks of equal sizes after which quantization by SVD is carried out on each block followed by WDR technique. Reconstruction is carried out by decompressing each blocks bit streams and then merging all of them to obtain the decompressed image. The visual and quantitative experimental results of the proposed image compression technique are shown and also compared with those of the WDR technique and JPEG2000. From the results of the comparison, the proposed image compression technique outperforms the WDR and JPEG2000 techniques.
\end{abstract}

Keywords: Lossy Image Compression, Wavelet Difference Reduction, Block Processing, Singular Value Decomposition.

\section{INTRODUCTION}

With the growing demand for multimedia applications especially high definition images, efficient storage and transmission of images have been issues of great concern [1]-[4]. Image processing deals with the reduction of the amount of bits used to represent an image.

There are two categories of image compression techniques namely lossless and lossy image compression techniques [5], [6]. In lossless image compression, the original image can be perfectly recovered from the compressed image while in lossy compression the original image cannot be perfectly recovered from the compressed image because some information is lost as a result of compression. Lossless compression is used in applications with high requirements such as medical imaging. Lossy compression techniques are very popular because they offer higher compression ratio. The objective of image compression is to achieve as much compression as possible with little loss of information [7], [8].

In this research work, a new lossy compression technique which employs Singular value decomposition (SVD) and wavelet difference reduction (WDR) is presented. SVD is a lossy image compression technique which can be regarded as a quantization process where it reduces the physcovisual redundancies of the image [9], [10]. Wavelet transforms are used frequently in many image processing applications [11]-[13]. One of these applications is in image compression. WDR is one of the state-of-the-art techniques in image compression which uses wavelet transform. It is a lossy image compression technique which achieves compression by first taking the wavelet transform of the input image and then applying the difference reduction method on the transform values [14]-[17].

In the proposed compression technique, the input image is firstly divided into the equal sized blocks and each block is quantized using the SVD technique and then WDR compression is carried out on the output image from the SVD compression for further compression. The proposed technique has been tested on several well-known images such as, Lena, Peppers, Boat, and Airfield. The results of this technique have been compared with those of JPEG2000 and WDR techniques. The quantitative experimental results based on PSNR show that the proposed technique overcomes the aforementioned techniques. The SVD and WDR image compression techniques are discussed in the next section. 


\section{RELATED WORK}

\subsection{Singular Value Decomposition}

SVD has been used in many image processing application [18-20]. Due to its nature, SVD has been always an important mathematical tool for image compression [21-23]. An image is represented by a matrix in digital form. SVD is a technique used to decompose a given matrix $\mathrm{A}$, into three matrices $\mathrm{U}, \Sigma$, and $\mathrm{V}$. U and $\mathrm{V}$ are orthogonal while $\Sigma$ is a diagonal matrix containing the singular values A [24-26]. $\Sigma$ can be approximated by ignoring small singular values. This approximation will result into a lower rank singular matrix. In order to reconstruct the input matrix, $\mathrm{U}$ and $\mathrm{V}$ matrices also need to be updated. Eqn. (1) shows the reconstruction of the input matrix with approximated $\Sigma$.

$$
\begin{aligned}
& A_{m \times n}=U_{m \times p} \bar{\Sigma}_{p \times q}\left(V_{n \times q}\right)^{T} \\
& \text { where } U_{m \times m}=\left[\begin{array}{ll}
U_{m \times p} & U_{m \times(m-p)}
\end{array}\right] \quad, \quad V_{n \times n}=\left[\begin{array}{ll}
V_{n \times q} & V_{n \times(n-q)}
\end{array}\right]
\end{aligned}
$$

The SVD compression is a lossy compression technique because singular values of the image are ignored in the procedure cannot be recovered, which results in losses [21], [26].

\subsection{Wavelet Difference Reduction}

Wavelet transformations have been employed in many of applications of computer vision in last couple of decays [27-29]. The WDR is a compression technique based on the difference reduction method. The wavelet transform of the input image is first taken; bit plane encoding is then applied to the transform values. The bit plane encoding procedure starts with the initialization stage, where a threshold $T_{o}$ is chosen such that To is greater than all the transform values and at least one of the transform values has a magnitude of $T_{d} / 2$. The next stage is the initialization stage where the threshold $T=T_{k-1}$ is updated to $T=T_{k}$, where $T_{k}=T_{k-1 / 2}$. New significant transform values (w(i)) which are satisfying $T \leq|w(i)| \leq$ $2 T$ are then identified at the significant pass stage. The transform values of these significant transform values are then encoded using the difference reduction method. At the significant pass stage, already quantized values $\left(w_{Q}\right)$ which satisfy $\left|w_{Q}\right| \geq 2 T$ are then refined in order to reduce error [30-32].

\section{THE PROPOSED TECHNIQUE}

The proposed image compression technique is a lossy compression technique. It begins by dividing the input image into equal sized blocks. In this work block sizes $16 \times 16,32 \times 32,64 \times 64$, and $128 \times 128$ are investigated for input images of size $256 \times 256$. SVD compression is then carried out on each block. As it was mentioned in the previous section, the SVD based compression is lossy due to the nature of the process. However the qualitative loss is not psychovisually noticeable up to some point. After SVD compression, WDR compression is carried out to further compress the image. The compression ratio is obtained by multiplication of the compression ratio obtained by using SVD with that of WDR. The compression ratio of WDR in the proposed block based compression technique is calculated by dividing the total number of bits required for representing the original image by the total number of bits stream which obtained by WDR. Decompression is carried out by taking the inverse WDR of the bit streams in order to reconstruct each block and then all blocks are combined together to form the decompressed image.

The block diagram of the proposed image compression technique is shown in Figure 1. The experimental qualitative and quantitative results are represented and discussed in the next section. 

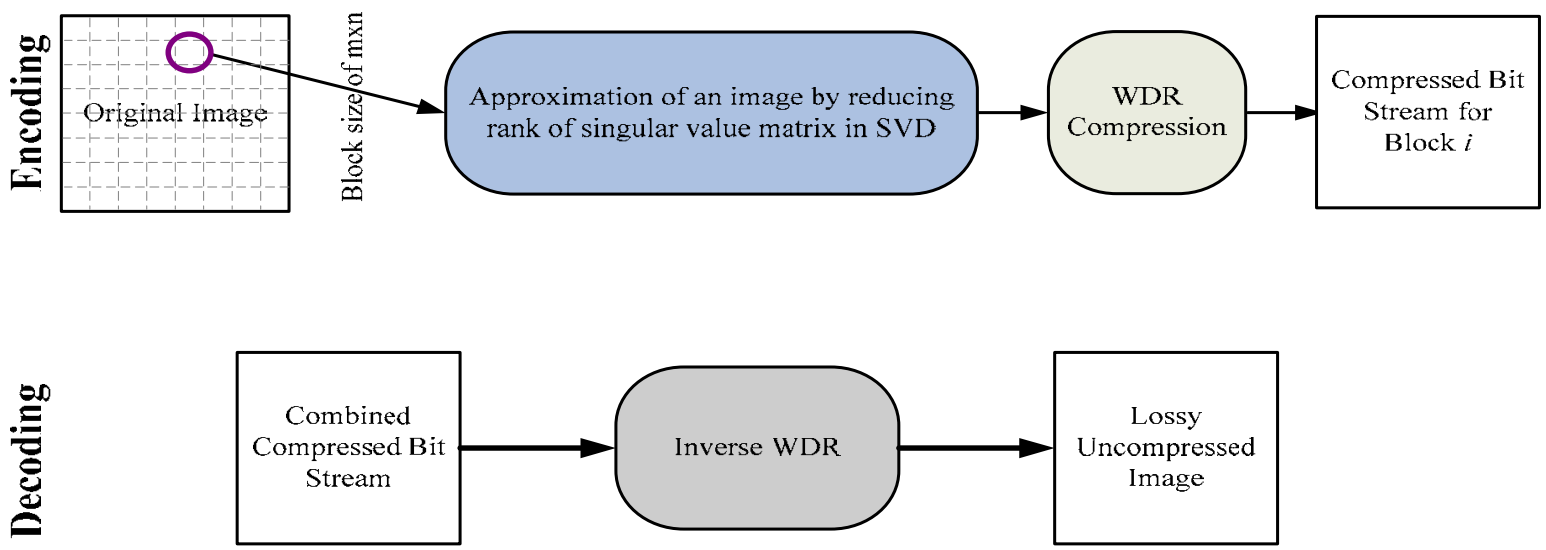

Figure 1: The block diagram of the proposed blocked based lossy image compression technique.

\section{EXPERIMENTAL RESULTS AND DISCUSSION}

The proposed lossy image compression, as it was mentioned in the Introduction, was tested on Airfield, Boats, Lena and Peppers images. All the input images are 256x256, 8-bit grey scale. Table 1 and 2 are showing the quantitative comparison between the proposed techniques and JPEG2000 and WDR by use of PSNR for compression ratio of 60:1 and 80:1 respectively.

Table 1: PSNR values in $\mathrm{dB}$ for 60:1 compression

\begin{tabular}{|l|l|l|l|}
\hline Image/Technique & Proposed Technique & JPEG2000 & WDR \\
\hline Airfield & 42.23 & 23.76 & 23.71 \\
\hline Boats & 43.45 & 28.26 & 28.14 \\
\hline Lena & 44.75 & 31.18 & 31.71 \\
\hline Peppers & 44.50 & 30.96 & 30.29 \\
\hline
\end{tabular}

Table 2: PSNR values in $\mathrm{dB}$ for 80:1 compression

\begin{tabular}{|l|l|l|l|}
\hline Image/ Technique & Proposed Technique & JPEG2000 & WDR \\
\hline Airfield & 41.45 & 22.64 & 22.71 \\
\hline Boats & 43.00 & 26.76 & 26.82 \\
\hline Lena & 44.24 & 29.62 & 29.71 \\
\hline Peppers & 44.22 & 29.54 & 28.93 \\
\hline
\end{tabular}

As the PSNR values shows in Table 1 and 2 the performance of the proposed technique overcomes the JPEG2000 and WDR based image compression techniques. Figure 2 is showing a portion of the magnified Lena image being compressed with compression ratio of $60: 1$ by using JPEG200, WDR, and the proposed technique with block size of $64 \times 64$. 


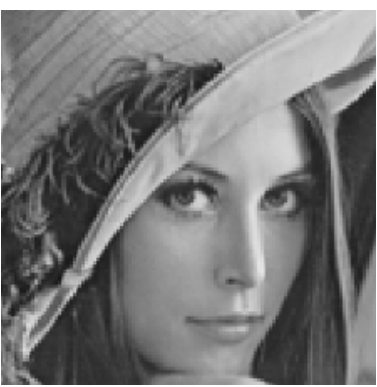

(a)

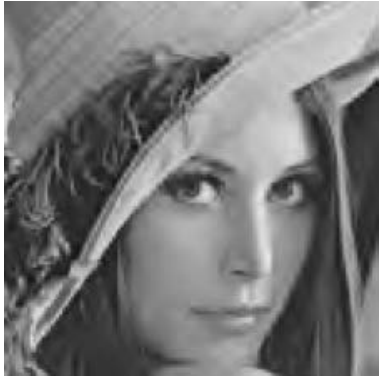

(c)

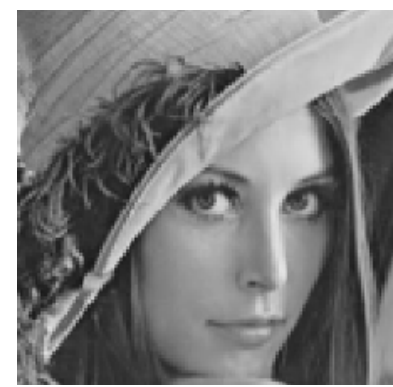

(b)

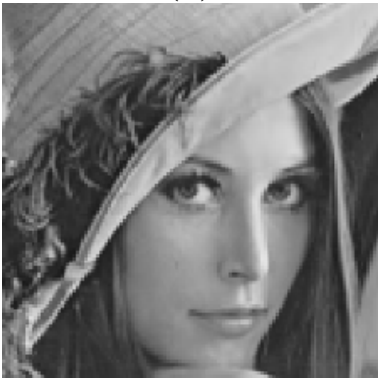

(d)

Figure 2: Zoomed (a) original Lena image, and compressed images by using (b) JPEG2000, (c) WDR, and (d) the proposed image compression technique using 64x64 block sizes at 60:1 compression ratio.

Figure 3 is illustrating PSNR versus the compression ratio for the aforementioned images comparing the JPEG2000 and WDR techniques and the proposed block based lossy image compression technique with $128 \times 128$ block sizes. The graphs are showing the superiority of the proposed image compression over the other state-of-the-art techniques.

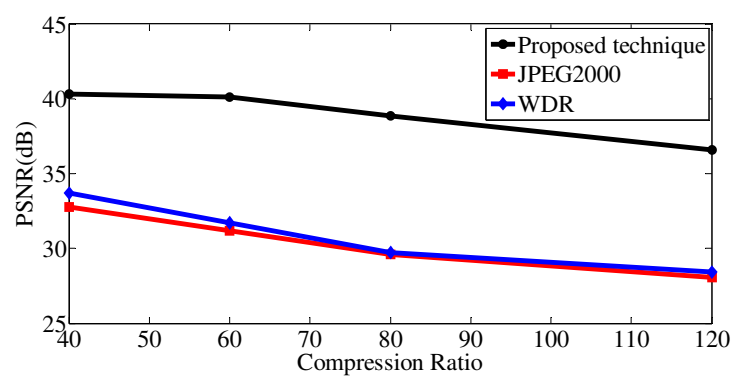

(a)

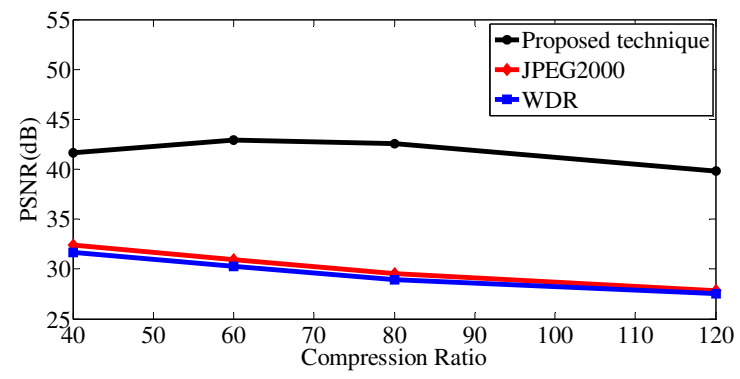

(c)

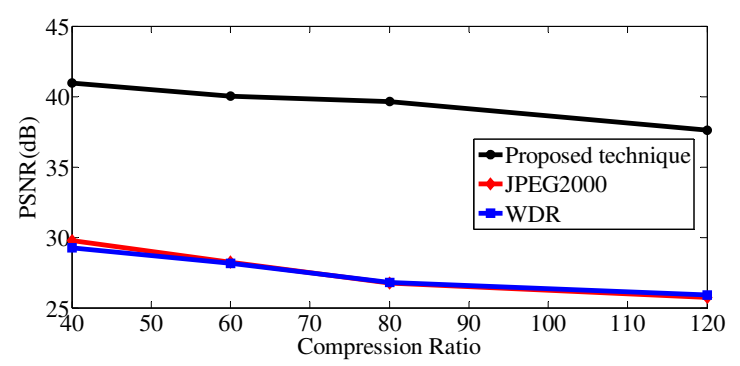

(b)

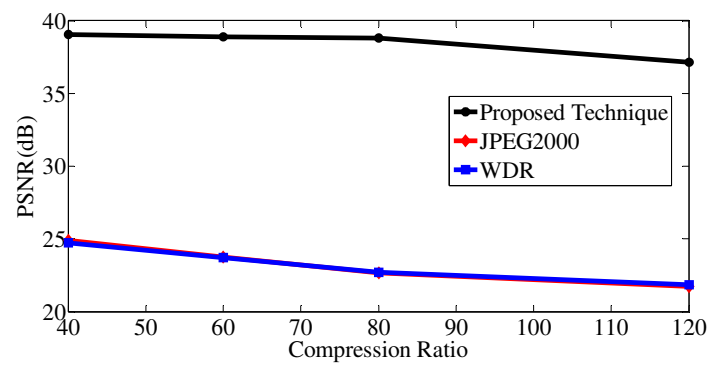

(d)

Figure 3: The PSNR (in dB) versus compression ratio for (a) Lena, (b) Boat, (c) Peppers, and (d) airfield images in which the block size of the proposed technique is $128 \times 128$. 


\section{CONCLUSION}

This paper was proposing a new block based lossy image compression technique which uses rank reduction and WDR technique. The input image is divided into blocks of equal sizes. Then each block was quantized by reducing its rank using SVD and then compressed by applying WDR technique. Reconstruction was carried out by decompressing each blocks bit streams and then merging all of them to obtain the decompressed image. The proposed image compression technique was compared with WDR technique and JPEG2000. The excremental results were showing that the proposed image compression technique outperforms the WDR and JPEG2000 techniques.

\section{REFERENCES}

[1] T. Fujii, D. Shirai, Y. Tonomura, M. Kitamura, T. Nakachi, T. Sawabe, M. Ogawara, T. Yamaguchi, M. Nomura, and K. Shirakawa, "Digital Cinema and Super-High-Definition Content Distribution on Optical High-Speed Networks", Proceedings of the IEEE, Vol. 101, pp. 140 - 153, (2013).

[2] A. Qian, C. Rongguan, N. Ning, S. Guozhi, Z. Xiaochen, Z. Jie, and K. Deyu, "High-Definition Image Processing Algorithm and Digital Platform Design", International Conference on Computer and Information Technology, pp. 798 - 800, (2012).

[3] K. Ishimaru, T. Fujii, T. Sawabe, J. Suzuki, and S. Ono, "Transmission characteristics of MPEG2 encoded super high definition images", Global Telecommunications Conference, Vol. 1, pp. 289 - 293, (1996).

[4] C. Tsan-Jieh, C. Herming, H. Chih-Cheng, Y. Chin, C. Wen-Hsu, T. Hann-Huei, and C. Chin-Fong, "High Definition Image PreProcessing System for Multi-Stripe Satellites' Image Sensors”, IEEE Sensors Journal, Vol. 12, pp. 2859 - 2865, (2012).

[5] M. Groach and A. Garg, "DCSPIHT: Image Compression Algorithm", International Journal of Engineering Research and Applications, Vol. 2, pp.560-567, (2012).

[6] S. Jayaraman, S. Esakkirajan, and T. Veerakumar, Digital Image Processing, Tata McGraw-Hill Education, $1^{\text {st }}$ Edition, (2009).

[7] M. Boliek, "Beyond compression: a survey of functionality derived from still image coding", IEEE Conference on Signals, Systems and Computers, Vol. 2, pp. 1971-1974, (2004).

[8] R. C. Gonzalez and R. E. Woods, Digital Image Processing, Prentice Hall, ${ }^{\text {nd }}$ Edition, (2002).

[9] J. F. Yang and C. L. Lu, "Combined Techniques Of Singular Value Decomposition and Vector Quantization For Image Coding", IEEE Transactions on Image Processing, Vol.4, pp.1141 - 1146, (1995).

[10] M. Greenberg, Differential equations \& Linear algebra, Prentice Hall, $1^{\text {st }}$ Edition, (2001).

[11] G. Anbarjafari and H. Demirel, "Image Super Resolution Based on Interpolation of Wavelet Domain High Frequency Subbands and the Spatial Domain Input Image", ETRI Journal, Vol. 32, No. 3, pp. 390-394, (2010).

[12] A. Karami, M. Yazdi, G. Mercier, "Compression of Hyperspectral Images Using Discerete Wavelet Transform and Tucker Decomposition", IEEE Journal of Selected Topics in Applied Earth Observations and Remote Sensing, Vol. 5, pp. 444-450, (2012).

[13] Cagri Ozcinar, Gholamreza Anbarjafari, Sara Izadpanahi, and Hasan Demirel, "Video Resolution Enhancement By Using Complex Wavelet Transform", International Conference on Image Processing, pp. 2093 - 2096, (2011).

[14] J. Tian and R.O. Wells, Jr, “A lossy image codec based on index coding”, IEEE Data Compression Conference, pp. 456 - 468 , (1996).

[15] J. Tian and R.O. Wells, Jr. "Embedded image coding using wavelet difference-reduction: Wavelet Image and Video Compression”, P. Topiwala, Ed., Kluwer Academic Publication, Norwell, MA, pp. 289-301, (1998).

[16] J. Tian and R.O. Wells, Jr., "Image data processing in the compressed wavelet domain", $3^{\text {rd }}$ International Conference on Signal Processing, B. Yuan and X. Tang Eds., pp. 978 - 981, (1996).

[17] S. P. Raja and A. Suruliandi, "Image Compression Using WDR and ASWDR Techniques With Different Wavelet Codecs", ACEEE International Journal on Information Technology, Vol. 01, pp. 23 - 26, (2011).

[18] X. Lu, H. Yuan, P. Yan, L. Li, and X. Li, "Image Denoising via Improved Sparse Coding”, British Machine Vision Conference, pp. 1-11, (2011).

[19] H. Demirel, G. Anbarjafari, and M. N. S. Jahromi, "Image equalization based on singular value decomposition", $23^{\text {rd }}$ IEEE International Conference on Computer and Information Sciences, pp. 1-5, (2008).

[20] T.J. Chin and D. Suter, "Incremental Kernel PCA for Efficient Non-linear Feature Extraction", British Machine Vision Conference, pp. 939-948, (2006).

[21] A. M. Rufai, G. Anbarjafari, and H. Demirel, "Lossy image compression using singular value decomposition and wavelet difference reduction", Digital Signal Processing, Vol. 24, pp. 117-123, (2014). 
[22] K. L. Chung, C. H. Shen, and L. C. Chang, "A novel SVD-and VQ-based image hiding scheme", Pattern Recognition Letters, Vol. 22, No. 9, pp. 1051-1058, (2001).

[23] L. Dongdong, L. Kai, H. Bo, Z. Zhengping, Z. Yan, and T. Fuxiao, "Image Compression Transmission Algorithm Based on the Singular Value Decomposition Applied in the Wireless Multimedia Sensor Networks”, Complexity, Vol. 8, No.3, pp.1, (2015).

[24] D. Kalman, “A Singularly Valuable Decomposition”, The College Mahtematics Journal, Vol.27, pp. 2 - 23, (1998).

[25] Nivedita, S. Jindal,"Performance Analysis of SVD and SPIHT Algorithm for Image Compression Application", International Journal of Advanced Research in Computer Science and Software Engineering, Vol. 2, (2012).

[26] L. Knochaert, B. De Backer, and D. De Zutter, "SVD compression, unitary transforms, and computational complexity", IEEE Transaction on Signal Processing, Vol. 47, pp. 2724-2729, (1999).

[27] M. Antonini, M. Barlaud, P. Mathieu, and I. Daubechies, "Image coding using wavelet transform", IEEE Transactions on Image Processing, Vol. 1, No. 2, pp. 205-220, (1992).

[28] G. Plonka, S. Tenorth, and A. Iske, "Optimally sparse image representation by the easy path wavelet transform", International Journal of Wavelets, Multiresolution and Information Processing, Vol. 10, No.1, (2012).

[29] W. J. Zhao, M. J. Zhao, and J. Pan, “The Image Compression Technology Based on Wavelet Transform”, Advanced Materials Research, Vol. 1078, pp. 370-374, (2015).

[30] Y. Yuan and M. K. Mandal, "Novel embedded image coding algorithms based on wavelet difference reduction", IEE Proceedings on Vision, Image and Signal Processing, Vol. 152, pp. 9 - 19, (2005).

[31] J. S. Walker, T. Q. Nguyen, and Y.Chen, "A Low-power, Low-memory System for Wavelet-based Image Compression”, Optical Engineering, Research Signposts, Vol. 5, pp. 111-125, (2003).

[32] J. S. Walker and T. Q. Nguyen, "Wavelet-based image compression", Chap. 6 in Handbook of Transforms and Data Compression, K.R. Rao and P. Yip, Eds., pp. 267-312, CRC Press, Boca Raton, (2001). 